\title{
Papers
}

\section{$\beta$ blockers for elective surgery in elderly patients: population based, retrospective cohort study}

Donald A Redelmeier, Damon C Scales, Alexander Kopp

\begin{abstract}
Objective To test whether atenolol (a long acting $\beta$ blocker) and metoprolol (a short acting $\beta$ blocker) are associated with equivalent reductions in risk for elderly patients undergoing elective surgery.

Design Population based, retrospective cohort analysis. Setting Acute care hospitals in Ontario, Canada, over one decade.

Participants Consecutive patients older than 65 who were admitted for elective surgery, without symptomatic coronary disease.

Main outcome measure Death or myocardial infarction. Results 37151 patients were receiving atenolol or metoprolol before surgery, of which the most common operations were orthopaedic or abdominal procedures. As expected, the two groups were similar in demographic characteristics, medical therapy, and type of surgery. 1038 patients experienced a myocardial infarction or died, a rate that was significantly lower for patients receiving atenolol than for those receiving metoprolol $(2.5 \%$ v $3.2 \%, \mathrm{P}<0.001)$. The decreased risk with atenolol persisted after adjustment for measured demographic, medical, and surgical factors; extended to comparisons of other long acting and short acting $\beta$ blockers; was accentuated in analyses that focused on patients with the clearest evidence of $\beta$ blocker treatment; and reflected the immediate postoperative interval.

Conclusions Patients receiving metoprolol do not have as low a perioperative cardiac risk as patients receiving atenolol, in accord with possible acute withdrawal after missed doses.
\end{abstract}

\section{Introduction}

Myocardial infarction and death are common, serious, and upsetting perioperative complications, especially after elective surgery. ${ }^{1-3} \beta$ blockers are a medical treatment that may reduce the perioperative cardiac risk associated with surgery. ${ }^{4-6}$ In randomised trials with results that reached significance, rates of cardiac mortality were $55-90 \%$ lower in patients given $\beta$ blockers than in controls. ${ }^{7}$ Comparisons of the relative effectiveness of different $\beta$ blockers have rarely been conducted, ${ }^{8}$ and clinicians often assume a general class effect shared by all agents. ${ }^{9}{ }^{10}$ From a theoretical perspective, $\beta$ blockers should offer similar protection, particularly if matched on cardiac selectivity and membrane stabilising activity. ${ }^{11}$ On the basis of this rationale, the choice among different $\beta$ blockers in clinical practice is often made in an arbitrary manner. ${ }^{12-15}$

Sudden withdrawal of $\beta$ blockers may result in a complicated syndrome marked by tachycardia, hypertension, and cardiac ischaemia. ${ }^{16-19}$ Similar to drug withdrawal from sedatives (for example, benzodiazepines), clinical manifestations tend to be accentuated in agents with rapid rather than extended elimination. ${ }^{20-24}$ Sudden withdrawal of $\beta$ blockers is particularly worrisome around the time of surgery because the loss of $\beta$ blockade may predispose patients to a myocardial infarction. ${ }^{25-29}$ For this reason, patients receiving $\beta$ blockers as outpatients are instructed to continue their medication around the time of surgery (including taking their medication on the morning of operation) and typically do not switch to a different agent in the same class. ${ }^{30-32}$ Furthermore, patients are typically prescribed the same $\beta$ blockers while in hospital after surgery as they had been originally receiving. ${ }^{33-37}$

Lapses in care are common in practice yet rarely documented in trials with strict protocols. ${ }^{38-40}$ Short acting medications may be particularly prone to problems related to missed doses because of both the greater opportunity for error (more doses needed) and the greater consequences from error (rapid withdrawal). ${ }^{41-45}$ Our theory was that short acting $\beta$ blockers may differ from long acting $\beta$ blockers in preventing perioperative myocardial infarction and death. In Ontario, atenolol and metoprolol are the most popular $\beta$ blockers; have similar indications and contraindications; and are both insured benefits in the health insurance plan. However, atenolol has a long duration of action and the typical dosage is once a day, whereas metoprolol has a shorter duration of action with a typical dosage twice a day, thereby enabling a natural comparison of these two active agents for elective surgery. ${ }^{46-48}$

\section{Methods}

We identified consecutive patients undergoing elective surgery in any hospital throughout Ontario, Canada, by using the database of the Canadian Institutes for Health Information, which provides the official data for ongoing accreditation and financial reimbursement in this setting. ${ }^{49}$ The accrual period was from 1 April 1992 to 1 April 2002 (10 years), representing all years available for analysis. We identified elderly patients (older than 65 ) admitted to hospital for elective surgery. We did not include outpatients, patients having surgery as a day procedure, or young individuals because of the generally low event rates in such circumstances. To reduce confounding from differing amounts of pre-existing illness, ${ }^{50}$ we excluded in advance patients with symptomatic coronary disease as evidenced by chronic use of nitrates. ${ }^{51}$

Characteristics of patients not having cardiac surgery are on bmj.com 
We made special efforts to gather population based data that eliminated referral bias and counted each patient only once. We deleted duplicate hospital records by retaining only one copy of events characterised as the same admission for the same patient on the same day. We analysed only the first admission for patients with more than one elective surgical procedure during the study interval (results based on separate admissions yielded more extreme results and are not reported). In addition, we counted outcomes after transfers according to the hospital first involved. We used confidentiality safeguards at the Institute for Clinical Evaluative Sciences in Ontario to conduct the study. All databases have been used extensively in past research..$^{52-54}$

\section{$\beta$ blockers}

For each patient we searched previously validated, population wide prescription records for the year before admission, ${ }^{55}{ }^{56}$ reasoning that $\beta$ blocker medications would probably be continued in the perioperative setting. We classified individual patients who received two or more prescriptions for atenolol as using this medication on an ongoing basis. Similarly, two or more prescriptions for metoprolol identified patients who used that $\beta$ blocker on an ongoing basis. We classified patients receiving two or more prescriptions for both atenolol and metoprolol as having mixed exposures and reported separately. We lacked direct individual data on medications received in hospital; however, to validate our classifications further we also identified prescriptions after discharge to confirm ongoing use of either atenolol or metoprolol among survivors.

We also considered some more complicated situations. We examined patients receiving two or more prescriptions of carvedilol, labetolol, oxprenolol, pindolol, timolol, or acebutolol in a secondary analysis of other short acting $\beta$ blockers. Similarly, we examined patients receiving two or more prescriptions for nadolol or bisoprolol in a secondary analysis of other long acting $\beta$ blockers. We considered patients receiving sustained release formulations of any $\beta$ blockers in the category of other long acting $\beta$ blockers and patients receiving multiple prescriptions of different short acting and long acting $\beta$ blockers a mixed group. We considered patients receiving two or more prescriptions for sotalol or propranolol each a unique group because of the distinct indications for these particular $\beta$ blockers.

\section{Outcome and characteristics}

We obtained information on patients' demographics by linking individuals to the Registered Persons database, the official governmental record for patients in Ontario. We obtained information on the nature of the surgical procedure and postoperative recovery from the Canadian Institutes for Health Information database. In addition, we classified operations according to type of surgery as either cardiac or non-cardiac, with non-cardiac surgery further distinguished as high risk noncardiac (thoracic, abdominal, retroperitoneal, vascular), medium risk non-cardiac (neurosurgical, external head and neck, unclassified), and low risk non-cardiac (lower urological and gynaecological, orthopaedic, breast and skin, ophthalmological). The available databases did not contain data on compliance, family history, or lifestyle.

We defined the primary outcome as death or myocardial infarction occurring during hospitalisation. ${ }^{57}$ Secondary analysis examined each end point separately. We also analysed non-cardiac complications after surgery to check for a lack of differences where no differences would be anticipated. These additional analyses of seven tracer conditions included wound infection, ileus, pneumonia, aspiration, respiratory failure, renal failure, and delirium. We further tested comparability between the two groups by examining five pre-specified, distinct, available measures of the process of care: transfusion of blood component; ultrasound of the abdomen; accidental cuts, puncture or perforation; foreign object left in body; and failure of dosing, instrument, or sterilisation.

\section{Statistical analysis}

We used the $\chi^{2}$ test to compare the frequency of death or myocardial infarction for patients receiving atenolol and metoprolol, because the data lacked the day of the postoperative infarction. We also used the log rank statistic to analyse dates of death alone. Additionally, we constructed a general predictive model by subjecting each baseline patient factor to stepwise logistic regression and thereby obtained an adjusted comparison of rates of death or myocardial infarction for patients receiving atenolol or metoprolol. A multivariable propensity score analysis, ${ }^{58}$ designed to adjust for clinical determinants of $\beta$ blocker selection, yielded results almost identical to those based on the general predictive model and are not reported (results same to two decimal places). All $\mathrm{P}$ values were two tailed, estimates calculated with $95 \%$ confidence intervals, and analyses conducted by using SAS software (version 8.02, Cary, NC 27513, USA).

\section{Results}

A total of 454336 elderly patients had a total of 634925 admissions for elective surgery across 252 separate hospitals during the 10 year interval. A minority of patients had symptomatic coronary disease $(n=48128)$, and most $(n=345253)$ had not received a $\beta$ blocker on an ongoing basis as an outpatient in the year before surgery. The most commonly used $\beta$ blockers were atenolol $(n=23091)$ and metoprolol $(n=14060)$, forming a ratio of about 5:3 that was stable over the decade. The median dose of atenolol was $50 \mathrm{mg}$ once daily and that of metoprolol 50 $\mathrm{mg}$ twice daily. Some patients received another long acting $\beta$ blocker $(n=2754)$, some another short acting $\beta$ blocker $(n=10668)$, and some had mixed exposures to a long acting as well as a short acting $\beta$ blocker $(n=229)$. The remaining patients were those receiving sotalol $(n=3810)$, propranolol $(n=6309)$, or either of these two medications in combination with another $\beta$ blocker $(\mathrm{n}=34)$.

As expected, the baseline characteristics for patients receiving atenolol or metoprolol overlapped substantially (table 1). The largest difference was in the proportion who had cardiac surgery, which was more common among those receiving metoprolol, although it was generally infrequent in both groups (an imbalance examined in subsequent analyses). After excluding patients undergoing cardiac surgery, the atenolol and metoprolol groups were remarkably similar in use of cardiac medications including statins, digoxin, furosemide, calcium channel blockers, angiotensin pathway blockers, and anticoagulants (see bmj.com for characteristics of patients not having cardiac surgery). We found no major differences between the two groups in other medications used to treat chronic medical and psychiatric conditions. We also found no clinically important differences in demographic characteristics between the two groups.

A total of 1038 patients experienced a myocardial infarction or died during their stay in hospital. The risk of this combined end point was one fifth lower for patients receiving atenolol rather than metoprolol $(2.5 \% v 3.2 \%, \mathrm{P}<0.001)$. The difference in risk was also apparent for the solitary end points of myocardial infarction $(1.6 \% \cup 2.0 \%, \mathrm{P}=0.004)$ and of death $(1.2 \% \cup 1.6 \%, \mathrm{P}=0.007)$. The difference persisted in those patients not having cardiac surgery, both for the combined end 
Table 1 Patients' characteristics. Values are numbers (percentages) of patients

\begin{tabular}{|c|c|c|}
\hline Characteristic & Atenolol $(\mathrm{n}=23$ 091) & $\begin{array}{c}\text { Metoprolol ( } \mathrm{n}=14 \\
060)\end{array}$ \\
\hline \multicolumn{3}{|l|}{ Age in years: } \\
\hline$\leq 69$ & 6932 (30) & $4000(28)$ \\
\hline $70-74$ & 7761 (34) & $4547(32)$ \\
\hline $75-79$ & $5929(26)$ & 3760 (27) \\
\hline$\geq 80$ & $2469(11)$ & $1753(12)$ \\
\hline \multicolumn{3}{|l|}{ Sex: } \\
\hline Female & $11758(51)$ & $6419(46)$ \\
\hline Male & $11333(49)$ & 7641 (54) \\
\hline \multicolumn{3}{|l|}{ Social status fifth: ${ }^{*}$} \\
\hline Lowest & $4535(20)$ & $2745(20)$ \\
\hline Next lowest & $5004(22)$ & 3044 (22) \\
\hline Middle & $4558(20)$ & $2688(19)$ \\
\hline Next highest & $3912(17)$ & $2469(18)$ \\
\hline Highest & 4275 (19) & $2566(18)$ \\
\hline Missing & $807(3)$ & $548(4)$ \\
\hline \multicolumn{3}{|l|}{ Medication in preceding year: $\dagger$} \\
\hline ACE inhibitor & $6681(29)$ & 4781 (34) \\
\hline Allopurinol & $1514(7)$ & $951(7)$ \\
\hline Antidepressant & $2135(9)$ & $1195(8)$ \\
\hline Benzodiazepine & $4641(20)$ & $2882(20)$ \\
\hline Bronchodilator & $1125(5)$ & $879(6)$ \\
\hline Calcium channel blocker & $6648(29)$ & $4148 \quad(30)$ \\
\hline Digoxin & $1456(6)$ & $1351(10)$ \\
\hline Furosemide & $1880(8)$ & $1813(13)$ \\
\hline Glaucoma eye drops & $1284(6)$ & $895(6)$ \\
\hline Glucocorticoid & $873(4)$ & $572(4)$ \\
\hline Gastric acid suppressor & $5197(23)$ & $3419(24)$ \\
\hline Insulin & $511(2)$ & $474(3)$ \\
\hline Levothyroxine & 2595 (11) & $1562(11)$ \\
\hline Antipsychotic & $332(1)$ & $223(2)$ \\
\hline Oral anticoagulant & $1434(6)$ & $1356(10)$ \\
\hline Oral antiplatelet agent & $312(1)$ & $222(2)$ \\
\hline Oral hypoglycaemic & $2211(10)$ & $1683(12)$ \\
\hline Statin & $4997(22)$ & $3632(26)$ \\
\hline \multicolumn{3}{|l|}{ Surgery type: } \\
\hline Cardiac & $2315(10)$ & $2047(15)$ \\
\hline Thoracic & $425(2)$ & $241(2)$ \\
\hline Abdominal & $5355(23)$ & $3172(23)$ \\
\hline Retroperitoneal & $321(1)$ & $180(1)$ \\
\hline Vascular & $2063(9)$ & $1334(9)$ \\
\hline Neurosurgical & $427(2)$ & $232(2)$ \\
\hline External head and neck & $655(3)$ & $381(3)$ \\
\hline Unclassified & $106(0)$ & $53(0)$ \\
\hline Lower urological or gynaecological & $4232(18)$ & $2443(17)$ \\
\hline Orthopaedic & $5108(22)$ & $2762(20)$ \\
\hline Breast or skin & $1198(5)$ & $659(5)$ \\
\hline Ophthalmological & $886(4)$ & $556(4)$ \\
\hline
\end{tabular}

*Derived from home neighbourhood income.

†Two or more presciptions in 12 months before admission.

łIncludes combined surgeries.

point $(2.0 \% v 2.6 \%, \mathrm{P}<0.001)$, and the solitary end points of myocardial infarction $(1.1 \% v 1.4 \%, \mathrm{P}=0.024)$ and death $(1.2 \% v$ $1.6 \%, \mathrm{P}=0.003)$. The pattern was consistent for high risk, medium risk, and low risk non-cardiac surgery and not apparent with cardiac surgery (fig 1). The relative risk reduction persisted in subgroups that excluded those patients receiving calcium channel blockers, furosemide, or other single cardiac medications.

We constructed a clinical prediction rule by taking into account each patient's baseline characteristics, concurrent medications, and type of surgery. The important independent predictors of myocardial infarction or death were the patient's age and sex; four medications (furosemide, calcium channel blockers, angiotensin converting enzyme (ACE) inhibitors, and statins); and type of surgery (table 2). The overall goodness of fit of this model was moderate (area under the receiver operating characteristic curve $0.74, \mathrm{P}<0.001$ ) and similar to past published perioperative prediction rules (area under the curve $0.60-0.65) .{ }^{60}$ The difference between atenolol and metoprolol persisted after adjusting for these predictors (relative risk reduction 13\%, 95\% confidence interval $1 \%$ to $22 \%$ ).

We conducted two further tests to gauge the robustness of our findings. A comparison of any long acting $\beta$ blocker (not just atenolol) to any short acting $\beta$ blocker (not just metoprolol) showed a $15 \%$ reduction in risk of myocardial infarction or death ( $5 \%$ to $24 \%$ ) before adjusting for the predictors and a $10 \%$ risk reduction after adjusting for the predictors $(0 \%$ to $19 \%)$. A comparison of those with confirmed ongoing use of atenolol or metoprolol (both defined as two or more prescriptions for the corresponding medication in the year after surgery) yielded a $45 \%$ reduction in risk of myocardial infarction $(31 \%$ to $56 \%)$ before adjusting for the predictors and a $35 \%$ risk reduction after adjusting for the predictors (19\% to 49\%).

We observed no differences between atenolol and metoprolol when we examined non-cardiac outcomes and processes of care after surgery that might be related to unmeasured characteristics of patients, surgical procedures, or hospitals. Postoperative wound infection was the most common complication and showed no significant difference between the two groups (table 3). Delirium was the second most common complication with a slight imbalance against the metoprolol group that was small in magnitude and did not reach significance $(\mathrm{P}=0.15)$. Postoperative pneumonia, renal failure, and prolonged ileus were all similar in frequency (each about $1 \%$ ), and the two groups did not differ significantly. Misadventures were rare, with no consistent imbalance between the two groups.

Most deaths occurred soon after admission, with postoperative day 3 as the most common. Differences between atenolol and metoprolol were primarily observed from postoperative days 2 through 14, in keeping with acute cardiac stress after surgery (fig 2). Differences between atenolol and metoprolol were not evident on the day of admission, in keeping with intraoperative catastrophes. Differences between atenolol and metoprolol were not evident beyond day 14, in keeping with delayed non-cardiac complications (and not easily explained by a selection bias that would entail an inherent ongoing difference in risk). No day showed a significant difference in mortality that favoured metoprolol. Analyses based on comparing any long acting $\beta$ blocker to any short acting $\beta$ blocker showed similar patterns.

\section{Discussion}

The risk of myocardial infarction and death for patients having non-cardiac surgery is lower for those receiving atenolol than for those receiving metoprolol, with a number needed to treat equal to about 165 patients to prevent one adverse event. We studied consecutive elderly patients having elective surgery over a 10 year interval and found that myocardial infarction and death were common complications, averaging about one event for every 36 hospitalisations. Given past research on the general effectiveness of $\beta$ blockers, these data imply a greater benefit with long acting $\beta$ blockers over short acting $\beta$ blockers in non-cardiac surgery. We found no postoperative complications that were significantly less common with metoprolol. In addition, we found that factors related to the patient and surgical 
Table 2 Independent predictors of myocardial infarction or death

Predictor variable Odds ratio $(95 \% \mathrm{Cl})$ Demographic characteristics:

\begin{tabular}{ll}
\hline Age $\geq 70^{*}$ & $1.41(1.22$ to 1.63$)$ \\
\hline Male sex & $1.37(1.20$ to 1.57$)$ \\
\hline Medications in preceding year: & \\
\hline Furosemide & $1.55(1.30$ to 1.85$)$ \\
\hline Calcium channel blocker & $1.17(1.03$ to 1.34$)$ \\
\hline ACE inhibitor & $1.17(1.02$ to 1.34$)$ \\
\hline Statin & $0.82(0.71$ to 0.95$)$ \\
\hline Surgery typet: & \\
\hline Cardiac & $2.57(2.17$ to 3.04$)$ \\
\hline Thoracic & $1.79(1.24$ to 2.60$)$ \\
\hline Vascular & $1.99(1.65$ to 2.40$)$ \\
\hline Lower urological or gynaecological & $0.21(0.15$ to 0.29$)$ \\
\hline Orthopaedic & $0.62(0.51$ to 0.76$)$ \\
\hline Breast or skin & $0.29(0.17$ to 0.50$)$ \\
\hline Ophthalmological & $0.05(0.01$ to 0.19$)$ \\
\hline
\end{tabular}

*Binary classification compared with younger age group.

†Comparison is abdominal, retroperitoneal, external head and neck, neurosurgical, unclassified.

procedure were still the major determinants of whether a patient experienced a major cardiac complication after the operation.
Table 3 Non-cardiac postoperative outcomes. Values are numbers (percentages) of patients unless otherwise indicated

\begin{tabular}{|c|c|c|c|}
\hline Outcome variable & $\begin{array}{l}\text { Atenolol group } \\
(\mathrm{n}=23 \text { 091) }\end{array}$ & $\begin{array}{c}\text { Metoprolol } \\
\text { group }(\mathrm{n}=14 \\
060)\end{array}$ & $P$ value \\
\hline \multicolumn{4}{|l|}{ Clinical complication (diagnosis codes*) } \\
\hline Wound infection (998.1 to 998.9) & $1385(6.0)$ & $900(6.4)$ & 0.159 \\
\hline Ileus (997.4) & $300(1.3)$ & $169(1.2)$ & 0.556 \\
\hline Pneumonia (480.0 to 487.9 ) & $208(0.9)$ & $141(1.0)$ & 0.746 \\
\hline Aspiration (507.0 to 507.8) & $46(0.2)$ & $28(0.2)$ & 0.415 \\
\hline Respiratory failure (518.8) & $23(0.1)$ & $14(0.1)$ & 0.857 \\
\hline Renal failure (997.5) & $231(1.0)$ & $141(1.0)$ & 0.675 \\
\hline Delirium (293.0 to 293.9) & $346(1.5)$ & $239(1.7)$ & 0.147 \\
\hline \multicolumn{4}{|l|}{ Technical procedure (procedure codest) } \\
\hline Transfusion of blood component (130) & $208(0.9)$ & $141(1.0)$ & 0.386 \\
\hline Ultrasound of the abdomen (286) & $92(0.4)$ & $56(0.4)$ & 0.401 \\
\hline \multicolumn{4}{|l|}{ Medical error (external factor codes*) } \\
\hline $\begin{array}{l}\text { Accidental cut, puncture, perforation } \\
\text { (E870) }\end{array}$ & $217(0.94)$ & $109(0.78)$ & 0.099 \\
\hline Foreign object left in body (E871) & $5(0.02)$ & $3(0.02)$ & 0.984 \\
\hline $\begin{array}{l}\text { Failure of dosing, instrument, sterilisation } \\
\text { (E872-E874) }\end{array}$ & $5(0.03)$ & $3(0.02)$ & 0.609 \\
\hline
\end{tabular}

*Based on International Classification of Diseases (9th revision).

†Based on Canadian Procedure Codes.

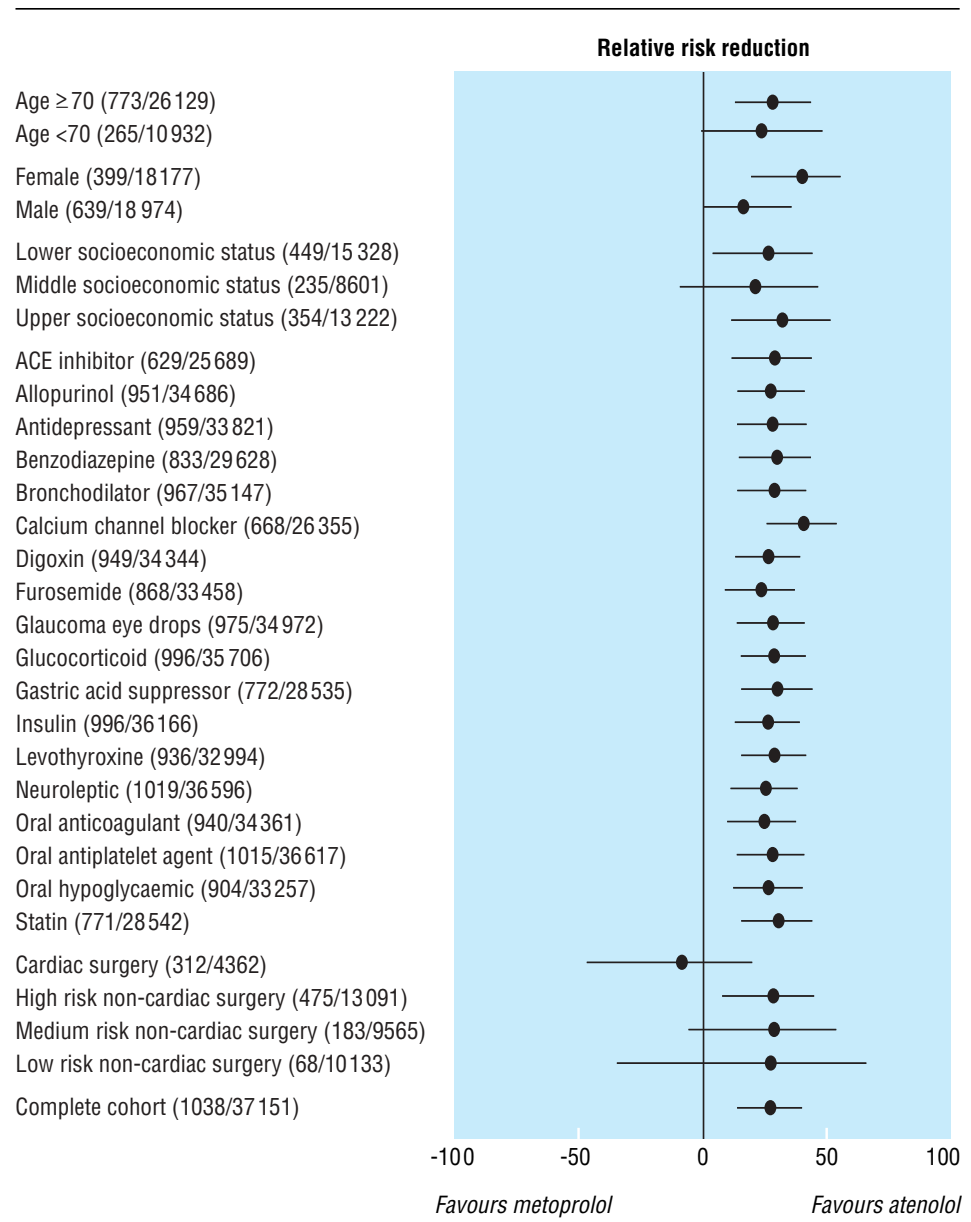

Fig 1 Relative reduction in risk of death or myocardial infarction. Relative risk of myocardial infarction or death for patients receiving atenolol compared with patients receiving metoproplol. A $x$ axis value of 0 denotes the null effect, where risk with atenolol equals risk with metoprolol. Values to the right of 0 indicate a relative risk reduction in favour of atenolol. Baseline risk in each analysis shown in parentheses as total number of events and total sample size. Complete cohort analysis appears at the bottom, showing a $23 \%$ relative reduction in the risk of myocardial infarction or death for patients prescribed atenolol compared with patients prescribed metoprolol (95\% confidence interval 13 to 32). The designated medication subgroups exclude those receiving the corresponding agent. For example, the 15th line shows that for the subgroup of patients not receiving furosemide, atenolol is associated with a $20 \%$ reduction in the risk of myocardial infarction or death ( 9 to 30 ) 


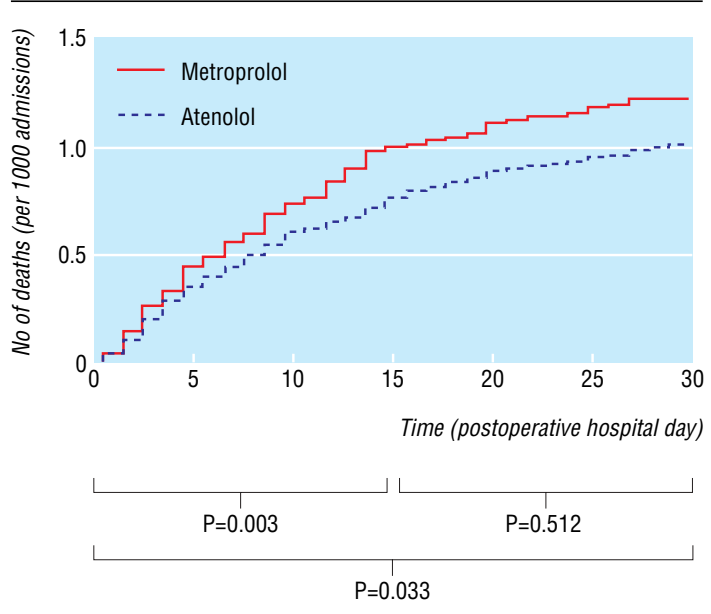

Fig 2 Absolute risk of death in hospital within 30 days of elective surgery. Absolute risk of death comparing atenolol with metoprolol after surgery. Data expressed as cumulative number of deaths per 1000 admissions on corresponding day. $\mathrm{P}$ values compare death rate with atenolol relative to metoprolol for entire interval and for consecutive 14 day intervals, using log rank test

\section{Limitations}

Our study is not a randomised trial and so the results might be exaggerated by hidden confounding. ${ }^{61}$ However, we examined a distinct situation where choosing between the two medications would not be strongly related to the patient's underlying severity of illnesses, and we excluded patients with symptomatic coronary disease. Results persisted across multiple stratified analyses adjusting for measured characteristics. Moreover, differences in risk were not apparent in non-cardiac outcomes (which would be expected to reflect unmeasured characteristics) and not apparent with cardiac surgery outcomes (which would be more related to graft failure and other anatomic factors). Furthermore, all the analyses are biased toward the null because of the random miscoding inherent in large databases, potentials for nonadherence and crossovers with drug treatment, and latent diagnostic errors whereby some myocardial infarctions go undetected in clinical practice.

\section{Randomised trials}

The ideal method to control hidden confounding is a randomised trial, yet such data are unlikely to be soon available for comparing different $\beta$ blockers. Firstly, such trials are awkward to conduct because they demand an enormous sample size ( $\mathrm{n}>10000$ for the difference observed in this study). Secondly, such trials are difficult to fund given that both medications are available in generic form and that grant reviewers might not hold equipoise (to explain away our observed association, an unmeasured factor would need to both double the odds of prescribing metoprolol over atenolol and triple the odds of death and myocardial infarction). Thirdly, such trials may face recruitment difficulties since patients who are receiving and tolerating ongoing treatment with a $\beta$ blocker may be reluctant to stop treatment in a randomised manner. Finally, our proposed mechanism related to inadvertent lapses leading to unintended $\beta$ blocker withdrawal would be missed in a highly controlled randomised trial with meticulous follow-up of patients.

\section{Exact timing}

The second large limitation of our research relates to the absence of direct data on the exact timing of $\beta$ blocker doses while in hospital (including recently started $\beta$ blockers initiated

\section{What is already known on this topic}

$\beta$ blocker medications can prevent perioperative myocardial infarction and death

Withdrawal of $\beta$ blockers can cause haemodynamic instability and myocardial ischaemia

Lapses occur in medical care, although these are rarely documented in clinical trials

\section{What this study adds}

Short acting $\beta$ blockers (such as metoprolol) are associated with less cardiac protection than long acting $\beta$ blockers (such as atenolol) in the perioperative setting

Switching from short acting to long acting $\beta$ blocker may prevent one myocardial infarction or death for every 165 patients with no offsetting increase in wound infection, delirium, or other common postoperative complications

preoperatively). We do not know how many patients had their $\beta$ blocker deliberately withheld around the time of surgery, but this decision would not be expected to differ between atenolol and metoprolol. We also have no direct evidence regarding inadvertently missed doses and whether the differences between atenolol and metoprolol were exclusively derived among appropriate patients who did not receive adequate $\beta$ blockade. Detection of missed doses has been studied previously, requires direct observation, and is arduous to complete on a large scale. ${ }^{62-64}$ Ironically, intrusive monitoring for missed doses can be misleading when the act of observation changes the behaviour of those being observed. ${ }^{65}$

Missed doses of $\beta$ blockers do not necessarily imply sloppy surgical care. Postoperative confusion may lead to unwitnessed spills, postoperative nausea may create swallowing difficulties, postoperative ileus may cause erratic intestinal absorption, postoperative hypotension may prompt intentionally held doses, and postoperative aspiration may lead to temporarily stopping all oral intake. Complex protocols contribute, such as when a patient is scheduled for an imaging procedure, taken to the radiology department, and not available for bedside care. Complex staffing is also a factor as clinicians have to make time for breaks, shifts, and other patients. In addition, simple errors can arise because so many factors need attention after surgery that it becomes easy for doctors to forget to write the order or for patients to miss a dose at some point.

\section{Conclusion}

Our study shows that patients receiving atenolol should not switch to metoprolol at the time of elective non-cardiac surgery. Patients receiving metoprolol, in contrast, may wish to consider switching to a longer acting agent (sustained release metoprolol is available but not widely marketed yet ${ }^{66}$ ). In addition, anaesthetists who initiate short acting $\beta$ blockers during surgery may wish to provide explicit mention in the chart so that the risk of subsequent $\beta$ blocker withdrawal is minimised on the ward at follow-up. To the extent that $\beta$ blockers prevent ischaemia and withdrawal of $\beta$ blockers triggers ischaemia, errors in their application will lead to commensurate increases in patient risk. Given that lapses in clinical care are inevitable, our data imply that long acting $\beta$ blockers provide a greater margin of safety for patients in the immediate postoperative period after elective non-cardiac surgery. 
We are indebted to the following people for helpful comments on specific points: Philip Devereaux, Edward Etchells, Gordon Guyatt, Daniel Hackam, David Juurlink, Martin Myers, Steven Shumak, Matthew Stanbrook, Thomas Stelfox, and Homer Tien

Contributors: All authors participated in the study design, interpretation of results, and approval of the final draft. DAR had full access to all the data in the study and final responsibility for the decision to submit for publication. He is guarantor.

Funding: Canada Research Chair in Medical Decision Sciences, the Canadian Institutes for Health Research, the National Institutes of Health Resuscitation Outcomes Consortium, and the Patient Safety Service of Sunnybrook and Women's College Health Sciences Centre.

Competing interests: None declared.

Ethical approval: Ethics committee of the Sunnybrook and Women's College Health Sciences Centre.

1 Ashton CM, Petersen NJ, Wray NP, Kiefe CI, Dunn JK, Wu L, et al. The incidence of perioperative myocardial infarction in men undergoing noncardiac surgery. Ann Intern Med 1993;118:504-10.

2 Browner WS, Li J, Mangano DT. In-hospital and long-term mortality in male veterans following non-cardiac surgery: the Study of Perioperative Ischemia Research Group. JAMA 1992;268:228-32.

3 Lawrence VA, Hilsenbeck SG, Mulrow CD, Dhanda R, Sapp J, Page CP. Incidence and hospital stay for cardiac and pulmonary complications after abdominal surgery. J Gen Intern Med 1995;10:671-8.

4 Mangano DT, Layug EL, Wallace A, Tateo I. Effect of atenolol on mortality and cardiovascular morbidity after noncardiac surgery: Multicenter Study of Perioperative Ischemia Research Group. N Engl J Med 1996;335:1713-20.

5 Poldermans D, Boersma E, Bax JJ, Thomson IR, van de Ven LL, Blankensteijn JD, et al. The effect of bisoprolol on perioperative mortality and myocardial infarction in highrisk patients undergoing vascular surgery. N Engl J Med 1999;341:1789-94.

6 Stevens RD, Burri H, Tramer MR. Pharmacologic myocardial protection in patients undergoing noncardiac surgery: a quantitative systematic review. Anesth Analg
2003:97:623-33.

7 Auerbach AD, Goldman L. Beta-blockers and reduction of cardiac events in noncardiac surgery. Scientific Review. JAMA 2002;287:1435-44.

8 Poole-Wilson PA, Swedberg K, Cleland JG, Di Lenarda A, Hanrath P, Komajda M, et al. Comparison of carvedilol and metoprolol on clinical outcomes in patients with chronic heart failure in the Carvedilol Or Metoprolol European Trial (COMET). Lancet 2003 Jul 5;362(9377):7-13.

9 McAlister FA, Laupacis A, Wells GA, Sackett DL. Users' Guides to the Medical Literature: XIX. Applying clinical trial results B. Guidelines for determining whether a drug is exerting (more than) a class effect. JAMA 1999;282:1371-7.

10 Eagle KA, Berger PB, Calkins H, Chaitman BR, Ewy GA, Fleischmann KE, et al. ACC/ AHA guideline update for perioperative cardiovascular evaluation for noncardiac surgery-executive summary. J Am Coll Cardiol 2002;39:542-53.

11 Salpeter SR, Ormiston TM, Salpeter EE. Cardioselective beta-blockers in patients with Salpeter SR, Ormiston TM, Salpeter EE. Cardioselective beta-blockers in

12 Matty PJ, Manu P. Outpatient use of beta-blocking agents-prescribing preferences of physicians in training. J Clin Pharm Ther 1987;12:409-14

13 Armanious S, Wong DT, Etchells E, Higgins P, Chung F. Successful implementation of perioperative beta-blockade utilizing a multidisciplinary approach. Can J Anesth 2003;50:131-6.

14 VanDenKerkhof EG, Milne B, Parlow JL. Knowledge and practice regarding prophylactic perioperative beta blockade in patients undergoing noncardiac surgery: $A$ survey of Canadian anesthesiologists. Anesth Analg 2003;96:1558-65.

15 Redelmeier DA, Shafir E. Medical decision making in situations that offer multiple alternatives. JAMA 1995;273:302-5.

16 Boudoulas H, Lewis RP, Kates RE, Dalamangas G. Hypersensitivity to adrenergic stimulation after propranolol withdrawal in normal subjects. Ann Intern Med $1977 ; 87: 433-6$

17 Maling TJ, Dollery CT. Changes in blood pressure, heart rate, and plasma noradrenaline concentration after sudden withdrawal of propranolol. BMJ 1979;2:366-7.

18 Rangno RE, Langlois S, Lutterodt A. Metoprolol withdrawal phenomena: mechanism and prevention. Clin Pharmacol Ther 1982;31:8-15.

19 Houston MC, Hodge R. Beta-adrenergic blocker withdrawal syndromes in hypertension and other cardiovascular diseases. Am Heart J 1988;116:515-23.

20 Miller RR, Olson HG, Amsterdam EA, Mason DT. Propranolol withdrawal rebound phenomenon: exacerbations of coronary events after abrupt cessation of antianginal therapy. N Engl J Med 1975;293:416-8.

21 Webster J, Hawksworth GM, Barber HE, Jeffers TA, Petrie JC. Withdrawal of long-term therapy with atenolol in hypertensive patients. Br J Clin Pharmacol 1981;12:211-4

22 Reeves RA, Boer WH, DeLeve L, Leenen FH. Beta-blockade disappearance rate predicts beta-adrenergic hypersensitivity. Clin Pharmacol Ther 1989;46:279-90.

23 Nelson J, Chouinard G. Guidelines for the clinical use of benzodiazepines: pharmacokinetics, dependency, rebound and withdrawal. Canadian Society for Clinical Pharmacology. Can J Clin Pharmacol 1999;6:69-83.

24 Kosten TR, O'Connor PG. Management of drug and alcohol withdrawal. N Engl J Med 2003;348:1786-95

25 Alderman EL, Coltart DJ, Wettach GE, Harrison DC. Coronary artery syndromes after sudden propranolol withdrawal. Ann Intern Med 1974;81:625-7.

26 Langou RA, Wiles JC, Peduzzi PN, Hammond GL, Cohen LS. Incidence and mortality of perioperative myocardial infarction in patients undergoing coronary artery bypass of perioperative myocardial infarction in patient
grafting. Circulation 1977;56(3 suppl):I154-8.

27 Erafting. Circulation 1977;56(3 suppl):1154-8. therapy in chronic stable angina. Am J Cardiol 1988;61:1219-22.

28 Psaty BM, Koepsell TD, Wagner EH, LoGerfo JP, Inui TS. The relative risk of inciden coronary heart disease associated with recently stopping the use of beta-blockers. JAMA 1990;263:1653-7.
29 Shammash JB, Trost JC, Gold JM, Berlin JA, Golden MA, Kimmel SE. Perioperative beta-blocker withdrawal and mortality in vascular surgical patients. Am Heart J 2001;141:148-53.

30 Pinnock C, Lin T, Smith T, eds. Fundamentals of anaesthesia. London: Greenwich Medical Media, 1999:31

31 Miller RD, ed. Anesthesia, 5th edn. Philadelphia: Churchill Livingstone, 2000:559.

32 McFalls EO, Ward HB, Moritz TE. Coronary-artery revascularization before elective major vascular surgery. $N$ Engl J Med 2004;351:2795-804.

33 Tierney LM Jr, McPhee SJ, Papadakis MA, eds. Current medical diagnosis and treatment. 42nd edn. Toronto: Lange Medical Books, McGraw-Hill, 2003:30-1.

34 Fleisher LA, Eagle KA. Lowering cardiac risk in noncardiac surgery. $N$ Engl J Med 2001:345:1677-82

35 Shammash JB, Mohler ER III, Kimmel SE. Management of high-risk patients with vascular disease prior to major noncardiac surgery. In: Rose BD, ed. UpToDate. Wellesley, MA: UpToDate, 2004

36 Price DJ, Kluger MT, Fletcher T. The management of patients with ischaemic heart disease undergoing non-cardiac elective surgery: a survey of Australian and New Zealand clinical practice. Anaesthesia 2004;59:428-34.

37 Pass SE, Simpson RW. Discontinuation and reinstitution of medications during the perioperative period. Am J Health Syst Pharm 2004;61:899-912.

38 Barker KN, Flynn EA, Pepper GA, Bates DW, Mikeal RL. Medication errors observed in 36 health care facilities. Arch Intern Med 2002;162:1897-903.

39 Lindenauer PK, Fitzgerald J, Hoople N, Benjamin EM. The potential preventability of postoperative myocardial infarction: underuse of perioperative beta-adrenergic blockade. Arch Intern Med 2004;164:762-6.

40 Juurlink DN, Mamdani MM, Lee DS, Kopp A, Austin PC, Laupacis A, et al. Rates of hyperkalemia after publication of the randomized aldactone evaluation study. $N$ EnglJ Med 2004;351:543-51.

41 Szecsi E, Kohlschutter S, Schiess W, Lang E. Abrupt withdrawal of pindolol or metoprolol after chronic therapy. Br J Clin Pharmacol 1982;13:353S-357S.

42 Olsson G, Hjemdahl P, Rehnqvist N. Rebound phenomena following gradual withdrawal of chronic metoprolol treatment in patients with ischemic heart disease. $A m$ Heart J 1984;108:454-62.

43 Krukemyer JJ, Boudoulas H, Binkley PF, Lima JJ. Comparison of hypersensitivity to adrenergic stimulation after abrupt withdrawal of propranolol and nadolol: influence of half-life differences. Am Heart J 1990;120:572-9.

44 Leenen FH, Fourney A, Notman G, Tanner J. Persistence of anti-hypertensive effect after 'missed doses' of calcium antagonist with long (amlodipine) vs short (diltiazem) elimination half-life. Br J Clin Pharmacol 1996;41:83-8.

45 Nettleman MD, Bock MJ. The epidemiology of missed medication doses in hospitalized patients. Clin Perform Qual Health Care 1996;4:148-53.

46 Nilsson OR, Atterhog JH, Castenfors J, Jorfelt L, Karlberg BE, Thulin T, et al. A comparison of $100 \mathrm{mg}$ atenolol and $100 \mathrm{mg}$ metoprolol once a day at rest and during exercise in hypertensives. Acta Med Scand 1984;216:301-7.

47 Silas JH, Freestone S, Lennard MS, Ramsay LE. Comparison of two slow-release formulations of metoprolol with conventional metoprolol and atenolol in hypertensive patients. Br J Clin Pharmacol 1985;20:387-91

48 Crowe PF, Ferguson RJ. Comparison of the duration of antihypertensive action of atenolol and metoprolol over a 24-hour period. Curr Med Res Opin 1985;9:431-5.

49 Williams JI, Young W. Inventory of studies on the accuracy of Canadian health administrative databases. Technical report. Ottawa: Institute for Clinical Evaluative Sciences, 1996.

50 Rothman KJ, Greenland S. Modern epidemiology. 2nd ed. Philadelphia: Lippincott Williams \& Wilkins, 1998:144-5.

51 Jackevicius CA, Tu K, Filate WA, Brien SE, Tu JV. Trends in cardiovascular drug utilization and drug expenditures in Canada between 1996 and 2001. Can J Cardiol 2003:19:1359-66.

52 Williams JI, Young W. A summary of studies on the quality of health care administrative databases in Canada. In: Goel V, Williams JI, Anderson GM, Blackstien-Hirsch P, Fooks C, Naylor CD, eds. Patterns of health care in Ontario: the ICES practice atlas. 2nd ed. Ottawa: Canadian Medical Association, 1996:339-45.

53 Redelmeier DA, Tan SH, Booth GL. The treatment of unrelated disorders in patients with chronic medical diseases. N Engl J Med 1998;338:1516-20.

54 Bell CM, Redelmeier DA. Mortality among patients admitted to hospitals on weekends as compared with weekdays. $N$ Engl J Med 2001;345:663-8.

55 Levy AR, O'Brien BJ, Sellors C, Grootendorst P, Willison D. Coding accuracy of administrative drug claims in the Ontario drug benefit database. Can J Clin Pharmacol 2003; 10:67-71.

56 Juurlink DN, Herrmann N, Szalai JP, Kopp A, Redelmeier DA. Medical illness and the risk of suicide in the elderly. Arch Intern Med 2004;164:1179-84.

57 Austin PC, Daly PA, Tu JV. A multicenter study of the coding accuracy of hospital discharge administrative data for patients admitted to cardiac care units in Ontario. Am Heart J 2002;144:290-6.

58 Rosenbaum PR, Rubin DB. Reducing bias in observational studies using subclassification on the propensity score. J Am Stat Assoc 1984;79:516-24.

59 Cepeda MS, Boston R, Farrar JT, Strom BL. Comparison of logistic regression versus propensity score when the number of events is low and there are multiple confounders. Am J Epidemiol 2003;158:280-7.

60 Gilbert K, Larocque BJ, Patrick LT. Prospective evaluation of cardiac risk indices for patients undergoing elective surgery. Ann Intern Med 2000;133:356-9.

61 Deeks JJ, Dinnes J, D'Amico R, Sowden AJ, Sakarovitch C, Song F, et al. Evaluating nonrandomised intervention studies. Health Technol Assess 2003;7:1-173.

62 Beers MH, Munekata M, Storrie M. The accuracy of medication histories in the hospital medical records of elderly persons. J Am Geriatr Soc 1990;38:1183-7.

63 Lesar TS, Lomaestro BM, Pohl H. Medication-prescribing errors in a teaching hospital. A 9-year experience. Arch Intern Med 1997;157:1569-76.

64 Flynn EA, Barker KN, Pepper GA, Bates DW, Mikeal RL. Comparison of methods for detecting medication errors in 36 hospitals and skilled-nursing facilities. Am J Health Syst Pharm 2002:59:436-46.

65 Fletcher RH, Fletcher SW, Wagner EH. Clinical epidemiology-the essentials. 3rd ed. Baltimore: Lippincott Williams \& Wilkins, 1996:142-3.

66 Sandberg A, Blomqvist I, Jonsson UE, Lundborg P. Pharmacokinetic and pharmacodynamic properties of a new controlled-release formulation of metoprolol: a comparison with conventional tablets. Eur J Clin Pharmacol 1988;33(suppl):S9-14. 
(Accepted 23 August 2005)

doi 10.1136/bmj.38603.746944.3A

Sunnybrook and Women's College Health Sciences Centre, G-151, 2075 Bayview Ave, Ontario, Canada M4N 3M5

Donald Redelmeier professor of medicine

Department of Medicine, University of Toronto, Clinical Epidemiology and Health
Care Research Program, Sunnybrook and Women's College Health Sciences Centre

Damon Scales clinical associate

Institute for Clinical Evaluative Sciences, Sunnybrook and Women's College Health Sciences Centre

Alexander Kopp senior analyst

Correspondence to D A Redelmeier DAR@ICES.ON.CA 